\title{
Mitochondrial DNA and ACTN3 genotypes in Finnish elite endurance and sprint athletes
}

\author{
Anna-Kaisa Niemi ${ }^{1,2}$ and Kari Majamaa*,1,2 \\ ${ }^{1}$ Department of Neurology, University of Oulu, Oulu, Finland; ${ }^{2}$ Clinical Research Center, Oulu University Hospital, \\ Oulu, Finland
}

Differences in ACTN3 (alpha-actinin 3) genotypes have been reported among endurance and power athletes. Elite athletic performance in endurance sports should also depend on mitochondrial oxidative phosphorylation (OXPHOS) that produces ATP for muscle metabolism. We determined mitochondrial DNA (mtDNA) and ACTN3 genotypes in Finnish elite endurance $(n=52)$ and sprint $(n=89)$ athletes, and found that the frequencies of mtDNA haplogroups differed significantly between the two groups. Most notably, none of the endurance athletes belonged to haplogroup $K$ or subhaplogroup J2, both of which have previously been associated with longevity. The frequency of ACTN3 XX genotype was higher and that of RR was lower among Finnish endurance athletes, and, in addition, none of the top Finnish sprinters had the $X X$ genotype. Lack of $m t D N A$ haplogroup $K$ and subhaplogroup $\mathbf{2}$ among elite endurance athletes suggests that these haplogroups are 'uncoupling genomes'. Such genomes should not be beneficial to endurance-type athletic performance but should be beneficial to longevity, since uncoupling of OXPHOS reduces the production of ATP, reduces the release of reactive oxygen species and generates heat. European Journal of Human Genetics (2005) 13, 965-969. doi:10.1038/sj.ejhg.5201438;

published online 11 May 2005

Keywords: physical endurance; genetics; longevity

\section{Introduction}

Elite athletic performance is a complex trait, which displays a genetic trade-off between speed and endurance. ${ }^{1}$ The I allele of angiotensin-converting enzyme (ACE), for example, has been associated with good endurance performance $^{2-4}$ and the D allele with good sprint performance. ${ }^{5}$ Furthermore, the 577XX genotype of the ACTN3 (alpha-actinin 3) gene, leading to a loss of $\alpha$-actinin-3 in fast-twitch muscle fibres, is more common among endurance athletes, whereas the wild-type 577RR genotype is more common among sprinters. ${ }^{1}$ An association has also been suggested between good physical performance and polymorphisms in genes encoding proteins of mitochon-

*Correspondence: Professor K Majamaa, Department of Neurology, University of Oulu, PO Box 5000, FIN-90014 Oulu, Finland.

Tel: + 3588315 4526; Fax: + 3588315 4544;

E-mail: kari.majamaa@oulu.fi

Received 9 December 2004; revised 21 March 2005; accepted 12 April 2005; published online 11 May 2005 drial energy metabolism. A polymorphism in the uncoupling protein-2 gene has been associated with good exercise efficiency, ${ }^{6}$ and the $8794 \mathrm{C}>\mathrm{T}$ transition in the MTATP6 gene, which determines mitochondrial DNA (mtDNA) haplogroup A, has been associated with good performance in endurance running. ${ }^{7}$

Aerobic ATP generation by oxidative phosphorylation (OXPHOS) in the mitochondrial respiratory chain is a prerequisite for prolonged muscle exercise. Out of $>80$ subunits of the respiratory chain enzymes, 13 are encoded by mtDNA that is a 16568-bp maternally inherited genome. Interestingly, good aerobic performance has been found to be maternally inherited more often than paternally inherited. ${ }^{8,9}$ Furthermore, patients with mutations in mtDNA commonly present with exercise intolerance, muscle weakness and increased production of lactic acid. $^{10}$

An association has been found between several mtDNA control region polymorphisms and endurance capacity in 
sedentary men, ${ }^{11}$ and between morph variants of MTND5 and the level of maximum oxygen uptake, ${ }^{12}$ suggesting that certain mtDNA lineages may contribute to good aerobic performance. Endurance runners should have highly efficient ATP production by OXPHOS, whereas sprinters may rely more on anaerobic glycolysis. Despite the crucial role of mitochondrial function in endurance performance, and despite the recent data on lineagespecific differences in mtDNA, ${ }^{13,14}$ differences in mtDNA haplogroups between sprinters and endurance runners have not previously been reported. We therefore set out to study mtDNA haplogroup and subhaplogroup frequencies in Finnish track and field athletes competing at the top level in endurance or sprint events. Furthermore, ACTN3 genotypes were assessed as a possible confounding variable.

\section{Subjects and methods Subjects}

The subjects consisted of 141 Finnish elite track and field athletes (52 endurance athletes, 89 sprinters) including three pairs of twins (two among endurance athletes, one among sprinters) and five pairs of siblings (one among endurance athletes, four among the sprinters). Data on mtDNA haplogroup frequencies in 1060 Finnish control subjects were included in the analyses. ${ }^{15,16}$ Athletes were included, if they had participated in the national track and field championships and/or in a national-level crosscountry race. Their best achievements were requested and they were considered top athletes, if they had represented Finland in the European or World Track and Field Championships (20 endurance athletes, 23 sprinters). Endurance athletes were runners whose main event was a race between $800 \mathrm{~m}$ and a marathon, or walkers, and sprinters were athletes whose main event was a race between 100 and $400 \mathrm{~m}$, or a field event. The birthplace of the maternal grandmother of the athletes was determined. Among the endurance athletes, $77 \%$ of the maternal grandmothers had been born south from the $64^{\circ}$ latitude, and among the sprint athletes the corresponding figure was $82 \%$. Furthermore, $81 \%$ of the controls had been born in this part of the country. These figures suggest that the groups were homogenous in their geographical background.

The study was approved by the Ethics Committee of Oulu University Hospital, and the athletes signed a statement of informed consent. The samples were collected from the athletes at the main national training camps with the permission of the Finnish Athletic Association.

\footnotetext{
Methods

MtDNA haplogroup and subhaplogroup analyses Total DNA was isolated from the blood cells using a QIAamp Blood Kit (Qiagen, Hilden, Germany). The mtDNA hap-
}

logroups and subhaplogroups were determined by restriction fragment analysis, ${ }^{17,18}$ or, by direct sequencing if a restriction site was not available (Table 1). Sequence variation in the European population was used to identify the polymorphisms that determine the mtDNA subhaplogroups. $^{18,19}$ The allele status at position 8794 in MTATP6 was determined by direct sequencing.

ACTN3 genotyping ACTN3 genotypes have previously been found to differ between endurance and sprint athletes. ${ }^{1}$ We determined these in order to assess whether they were a confounding variable in association analyses of mtDNA haplogroups. They were determined based on the $\mathrm{C}>\mathrm{T}$ transition at nucleotide 1747 in exon 16 , which leads to the replacement of an arginine codon by a stop codon. ${ }^{21}$ Allele 577R (codon CGA) can be distinguished by the absence of a DdeI restriction site, and allele 577X (codon TGA) by its presence. ${ }^{22}$ Digested PCR fragments were separated by $2 \%$ Metaphor ${ }^{\circledR}$ Agarose (Cambrex Bio Science Rockland, Inc., Rockland, ME, USA) gel electrophoresis. In total, $40(77 \%)$ of the endurance athletes and $68(76 \%)$ of the sprinters, including one pair of twins, participated in the ACTN3 genotype analysis. Anonymous samples from 120 Finnish blood donors were used as controls.

Statistical analyses Exact test of population differentiation was used to assess differences in the frequencies of mtDNA haplogroups between the endurance and sprint athletes and to analyse differences in mtDNA haplogroup frequencies between the three ACTN3 genotypes.

\section{Results}

The frequencies of mtDNA haplogroups differed between the endurance and sprint athletes $(P=0.039)$ (Table 2). Most notably, the frequencies of haplogroups $\mathrm{J}$ and $\mathrm{K}$ were higher among the sprinters. Only one endurance athlete belonged to haplogroup J (1.9\%), whereas the frequency of this haplogroup among the sprinters was $6.7 \%$. Two of the sprinters belonged to subhaplogroup J2, while the remaining four sprinters and the endurance athlete belonged to subhaplogroup J1. None of the endurance athletes belonged to haplogroup $\mathrm{K}$, whereas the frequency of this haplogroup among the sprinters was 9.0\%. In addition, four endurance athletes $(6.6 \%)$ belonged to haplogroup I, but none of the sprinters. The frequencies of mtDNA haplogroup clusters (HV, KU, IWX, JT) did not differ significantly between the groups. None of the Finnish athletes harboured $8794 \mathrm{C}>\mathrm{T}$ in MTATP6.

The possibility of recent common maternal ancestors was examined by using information on the birthplaces of the maternal grandmothers of the subjects. We identified only two pairs of cases with identical mtDNA subhaplogroup and with the same city of origin of the grandmother. In both cases, the subjects belonged to 
Table 1 Polymorphisms used to determine mtDNA haplogroups and subhaplogroups

\begin{tabular}{|c|c|c|}
\hline $\begin{array}{l}\text { Haplogroup/ } \\
\text { subhaplogroup }\end{array}$ & Nucleotide variant & Restriction enzyme \\
\hline $\begin{array}{l}H \\
\mathrm{H} 1 \\
\mathrm{H} 2 \\
\mathrm{H} 3\end{array}$ & $\begin{array}{l}7028 C \\
3010 G>A \\
4769 A \\
6776 T>C\end{array}$ & $\begin{array}{l}\text {-Alul } \\
- \text { Hpy188III } \\
+ \text { Alul } \\
\text { NA }\end{array}$ \\
\hline$V_{\mathrm{V} 1}$ & $\begin{array}{l}4580 G>A \\
5263 C>T\end{array}$ & $\begin{array}{l}\text {-Hsp92II } \\
\text { - HaellI }\end{array}$ \\
\hline $\begin{array}{l}\text { U2 } \\
\text { U5 } \\
\text { U8 }\end{array}$ & $\begin{array}{l}12308 A>G \\
3720 A>G \\
9477 G>A \\
9698 T>C\end{array}$ & $\begin{array}{l}+D d e l^{\mathrm{a}} \\
+ \text { BseNI } \\
+ \text { Tsp509I } \\
\text { NA }\end{array}$ \\
\hline$K 1^{*}$ & $\begin{array}{l}12308 A>G \\
10398 A>G \\
9093 A>G\end{array}$ & $\begin{array}{l}+D d e l^{\mathrm{a}} \\
+D d e l \\
\text { NA }\end{array}$ \\
\hline $\begin{array}{l}T \\
\text { T1 } \\
\text { T2 }\end{array}$ & $\begin{array}{l}15607 A>G \\
12633 C>A \\
11812 A>G\end{array}$ & $\begin{array}{l}+ \text { Alul } \\
- \text { Avall } \\
\text { NA }\end{array}$ \\
\hline${ }_{j}^{J}$ & $\begin{array}{l}13708 G>A \\
3010 G>A \\
7476 C>T\end{array}$ & $\begin{array}{l}\text {-Mval } \\
\text { - Hpy188III } \\
\text {-Alul }\end{array}$ \\
\hline $\begin{array}{l}\text { W } \\
\text { W1 } \\
\text { W2 }\end{array}$ & $\begin{array}{l}8251 G>A \\
12669 C>T \\
9612 G>A\end{array}$ & $\begin{array}{l}+ \text { Avall } \\
+ \text { Ndell } \\
\text { NA }\end{array}$ \\
\hline $\begin{array}{l}11 \\
12\end{array}$ & $\begin{array}{l}1719 G>A \\
8251 G>A \\
6734 G>A \\
15758 A>G\end{array}$ & $\begin{array}{l}\text {-Ddel } \\
+ \text { Avall } \\
\text {-EcoRV } \\
+ \text { Ddel }\end{array}$ \\
\hline $\begin{array}{l}X \\
Z\end{array}$ & $\begin{array}{l}1719 G>A \\
10400 C>T\end{array}$ & $\begin{array}{l}\text {-Ddel } \\
+ \text { Alul }\end{array}$ \\
\hline
\end{tabular}

The haplogroups and subhaplogroups were determined by restriction fragment analysis, or by direct sequencing when no restriction site was available. Subhaplogroup $\mathrm{K} 1$ is defined by $1189 \mathrm{~T}>\mathrm{C},{ }^{19}$ and $9093 \mathrm{~A}>\mathrm{G}$ defines a subset of this subhaplogroup which appears to be fairly frequent among the Finns. ${ }^{18}$ Allele status at a variable site is reported relative to $\mathrm{rCRS}$. += gain of restriction site, $-=$ loss of restriction site, $N A=$ restriction site is not available.

${ }^{a}$ Restriction site created by use of a mismatched oligonucleotide. ${ }^{20}$

subhaplogroup H1. This subhaplogroup is frequent among the Finns suggesting that the possibility of a recent common maternal ancestor is low.

We found that the frequency of the 577XX genotype of ACTN3 was lower and that of 577RR higher among the sprinters than among the endurance runners, and when the groups were stratified into subsets on the basis of their best achievements, there was an inverse correlation $(P=0.03)$ between the frequency of 577XX and success in sprinting events (Figure 1). Furthermore, none of the top sprinters harboured the 577XX genotype. There were no differences in mtDNA haplogroup frequencies between the three ACTN3 genotypes $(P=0.98$; exact test of population differentiation).

\section{Discussion}

We found that the frequencies of mtDNA haplogroups differed significantly between Finnish endurance and sprint athletes. None of the endurance athletes belonged to either subhaplogroup $\mathrm{J} 2$ or haplogroup $\mathrm{K}$, whereas the combined frequency of these was $11.2 \%$ among the sprinters. The frequency of subhaplogroup J2 in the Finnish population is at least $1.5 \%$ and that of haplogroup $\mathrm{K} 3.0 \%$ making the combined frequency of these haplogroups among the Finns $4.5 \% .{ }^{15}$ Both haplogroup J and haplogroup $\mathrm{K}$ are minor in European populations and, therefore, small changes in the frequencies of the cases within study groups may abolish the significance of the statistical testing. Interestingly, however, an association has been found between haplogroup J and longevity ${ }^{16,24,25}$ and subhaplogroup J2 in particular is more frequent among the very old than among controls. ${ }^{16}$ Haplogroup $\mathrm{K}$ has also been associated with longevity, ${ }^{25,26}$ or shows a trend for increased frequency in the very old. ${ }^{16,24}$ Thus, the subhaplogroups that are found at an increased frequency among the very old are rare among endurance athletes suggesting complementarities between these data.

We found that the 577XX genotype of the ACTN3 gene was less common among Finnish sprinters and that none of the top sprinters harboured this genotype. A trade-off between endurance and sprint performance traits seems possible, since the 577XX genotype has been found at a higher frequency among endurance athletes than among sprinters, while none of the most successful sprinters has been found to harbour this genotype. ${ }^{1}$ These differences in the distribution of the ACTN3 genotypes did not, however, explain our finding that mtDNA haplogroups differ between the two groups of athletes. The $577 X X$ genotype of ACTN3 is present in approximately $16 \%$ of the world's population, ${ }^{21}$ and although it causes complete absence of $\alpha$-actinin-3 in fast-twitch skeletal muscle fibres, it is not associated with any clinical phenotype. $^{21,22}$

Endurance athletes should be a highly selected group in terms of efficiency of ATP production. The main function of the mitochondria is to produce ATP by OXPHOS, and while the uncoupling of OXPHOS generates heat, it concomitantly reduces the production of ATP due to decreased proton translocation across the mitochondrial inner membrane or due to proton leak via ATP synthase. ${ }^{27}$ Uncoupling of OXPHOS also lowers the production of reactive oxygen species (ROS), which are its oligatory by-products. $^{27,28}$ ROS may play a role in ageing, ${ }^{29,30}$ for interestingly, mice with enhanced mitochondrial uncoupling live longer ${ }^{31}$ and mice with deficient 
Table 2 Mitochondrial DNA haplogroup and subhaplogroup frequencies among the endurance and sprint athletes

\begin{tabular}{|c|c|c|c|c|c|c|}
\hline \multirow[t]{2}{*}{ Haplogroup } & \multicolumn{2}{|c|}{$\begin{array}{c}\text { Endurance } \\
(n=52)\end{array}$} & \multicolumn{2}{|c|}{ Sprint $(n=89)$} & \multicolumn{2}{|c|}{$\begin{array}{c}\text { Controls } \\
(n=1060)\end{array}$} \\
\hline & $n$ & $\%$ & $n$ & $\%$ & $n$ & $\%$ \\
\hline$H$ & 27 & 52 & 42 & 47 & 508 & 48 \\
\hline $\mathrm{H} 1$ & 13 & 25 & 22 & 25 & ND & ND \\
\hline $\mathrm{H} 2$ & 3 & 5.8 & 2 & 2.2 & ND & ND \\
\hline $\mathrm{H} 3$ & 1 & 1.9 & 3 & 3.4 & ND & ND \\
\hline $\mathrm{H}^{*}$ & 10 & 19 & 15 & 17 & ND & ND \\
\hline$v^{a}$ & 3 & 5.8 & 7 & 7.9 & 51 & 4.8 \\
\hline V1 & 0 & 0 & 2 & 2.2 & ND & ND \\
\hline $\mathrm{V}^{*}$ & 2 & 3.8 & 5 & 5.6 & ND & ND \\
\hline Pre-V & 1 & 1.9 & 0 & 0 & ND & ND \\
\hline$U$ & 11 & 21 & 13 & 15 & 253 & 24 \\
\hline U5 & 9 & 17 & 13 & 15 & ND & ND \\
\hline U8 & 1 & 1.9 & 0 & 0 & ND & ND \\
\hline$U^{*}$ & 1 & 1.9 & 0 & 0 & ND & ND \\
\hline$K$ & 0 & 0 & 8 & 9.0 & 48 & 4.5 \\
\hline $\mathrm{K} 1^{\mathrm{b}}$ & 0 & 0 & 5 & 5.6 & ND & ND \\
\hline $\mathrm{K}^{*}$ & 0 & 0 & 3 & 3.4 & ND & ND \\
\hline$T$ & 3 & 5.8 & 4 & 4.5 & 38 & 3.6 \\
\hline $\mathrm{T} 1$ & 2 & 3.8 & 2 & 2.2 & ND & ND \\
\hline $\mathrm{T} 2$ & 1 & 1.9 & 2 & 2.2 & ND & ND \\
\hline J & 1 & 1.9 & 6 & 6.7 & 51 & 4.8 \\
\hline 11 & 1 & 1.9 & 4 & 4.5 & ND & ND \\
\hline 12 & 0 & 0 & 2 & 2.2 & ND & ND \\
\hline W & 3 & 5.8 & 6 & 6.7 & 47 & 4.4 \\
\hline W1 & 1 & 1.9 & 3 & 3.4 & ND & ND \\
\hline W2 & 2 & 3.8 & 1 & 1.1 & ND & ND \\
\hline$W^{*}$ & 0 & 0 & 2 & 2.2 & ND & ND \\
\hline I & 4 & 7.7 & 0 & 0 & 30 & 2.8 \\
\hline 11 & 2 & 3.8 & 0 & 0 & ND & ND \\
\hline 12 & 2 & 3.8 & 0 & 0 & ND & ND \\
\hline$x$ & 0 & 0 & 2 & 2.3 & 12 & 1.1 \\
\hline Others & 0 & 0 & 1 & 1.1 & 22 & 2.1 \\
\hline
\end{tabular}

Samples that did not fall into any of the subhaplogroups shown are denoted by an asterisk $\left({ }^{*}\right)$.

${ }^{\mathrm{a}}$ One endurance athlete belonged to haplogroup pre- $\mathrm{V}$, harbouring 7028T (+7025Alul), 4580G (+4577Hsp92II), 14766C (-14766Msel) and $15904 \mathrm{C}(-15904 \mathrm{Msel})$ in the coding region and $16298 \mathrm{C}$ and $16362 \mathrm{C}$ in HVS-I. ${ }^{23}$

${ }^{b} \mathrm{~K} 1$ is a subhaplogroup of haplogroup $\mathrm{K}$ defined by $9093 \mathrm{~A}>\mathrm{G} .{ }^{18,19}$ Frequencies of mtDNA haplogroups among 1060 Finnish subjects are shown as controls. ${ }^{15,16} \mathrm{ND}=$ not determined.

uncoupling produce more ROS. ${ }^{32}$ An mtDNA genotype leading to less efficient OXPHOS and lower ATP production (an 'uncoupling genotype') would therefore produce less ROS as well ${ }^{33}$ and probably promote longevity. MtDNA polymorphisms that increase uncoupling and concomitant heat production may have been important in climatic adaptation, and may therefore have been subject to positive selection. ${ }^{14,34}$ Indeed, neutrality tests have

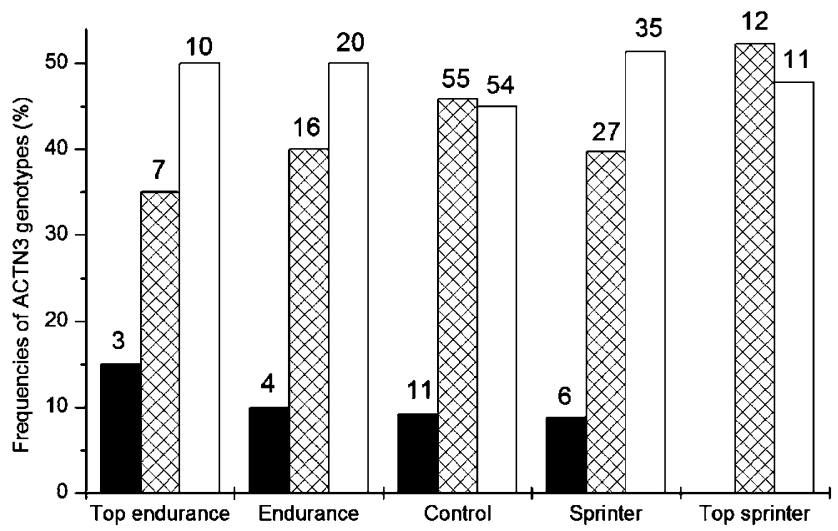

Figure 1 Frequencies of ACTN3 genotypes in Finnish track and field athletes and population controls. The endurance athletes and sprinters were both stratified into two subsets according to their best achievements. Solid bar, 577XX genotype; open bar, 577RR genotype; cross-hatched bar, 577RX genotype. Number of cases is shown above the bars.

revealed lineage-specific differences between the various European mtDNA haplogroups and haplogroup clusters, suggesting that mtDNA has evolved in a lineage-specific manner. ${ }^{13}$

We suggest that subhaplogroup $\mathrm{J} 2$ and haplogroup $\mathrm{K}$ are 'uncoupling genomes.' There are no previous studies on biochemical properties of cells harbouring different mtDNA lineages, but, interestingly, sperm cells harbouring mtDNA haplogroup $\mathrm{T}$ have been found to be slower in motility than cells harbouring haplogroup $\mathrm{H}^{35}$ This finding suggests that mtDNA lineages may differ in their functional properties. Functional or biochemical tests should reveal that a respiratory chain encoded by 'an uncoupling genome' produces less ROS and less ATP. Due to uncoupling, these genomes, such as haplogroup $\mathrm{K}$ and subhaplogroup $\mathrm{J} 2$, promote longevity ${ }^{16,24-26}$ but are not favourable in situations, where highly efficient ATP production is required, such as endurance athletic performance.

\section{Acknowledgements}

We thank Ms Anja Heikkinen and Ms Pirjo Keränen for their expert technical assistance. This study was supported by grants from the Sigrid Juselius Foundation, Suomen Urheilututkimussäätiö (the Finnish Sports Research Foundation) and the Medical Research Council of the Academy of Finland.

\section{References}

1 Yang N, MacArthur DG, Gulbin JP et al: ACTN3 genotype is associated with human elite athletic performance. Am J Hum Genet 2003; 73: 627-631.

2 Gayagay G, Yu B, Hambly B et al: Elite endurance athletes and the ACE I allele - the role of genes in athletic performance. Hum Genet 1998; 103: 48-50.

3 Myerson S, Hemingway H, Budget R, Martin J, Humphries S, Montgomery H: Human angiotensin I-converting enzyme gene and endurance performance. J Appl Physiol 1999; 87: 1313-1316. 
4 Collins M, Xenophontos SL, Cariolou MA et al: The ACE gene and endurance performance during the South African Ironman Triathlons. Med Sci Sports Exerc 2004; 36: 1314-1320.

5 Nazarov IB, Woods DR, Montgomery HE et al: The angiotensin converting enzyme I/D polymorphism in Russian athletes. Eur J Hum Genet 2001; 9: 797-801.

6 Buemann B, Schierning B, Toubro S et al: The association between the val/ala-55 polymorphism of the uncoupling protein 2 gene and exercise efficiency. Int J Obes Relat Metab Disord 2001; 25: $467-471$.

7 Tanaka M, Takeyasu T, Fuku N, Li-Jun G, Kurata M: Mitochondrial genome single nucleotide polymorphisms and their phenotypes in the Japanese. Ann NY Acad Sci 2004; 1011: 7-20.

8 Lesage R, Simoneau JA, Jobin J, Leblanc J, Bouchard C: Familial resemblance in maximal heart rate, blood lactate and aerobic power. Hum Hered 1985; 35: 182-189.

9 Perusse L, Gagnon J, Province MA et al: Familial aggregation of submaximal aerobic performance in the HERITAGE Family study. Med Sci Sports Exerc 2001; 33: 597-604.

10 Schmiedel J, Jackson S, Schafer J, Reichmann H: Mitochondrial cytopathies. J Neurol 2003; 250: 267-277.

11 Murakami H, Ota A, Simojo H, Okada M, Ajisaka R, Kuno S: Polymorphisms in control region of mtDNA relates to individual differences in endurance capacity or trainability. Jpn J Physiol 2001; 52: 247-256.

12 Dionne FT, Turcotte L, Thibault MC, Boulay MR, Skinner JS, Bouchard C: Mitochondrial DNA sequence polymorphism, VO2max, and response to endurance training. Med Sci Sports Exerc 1991; 23: 177-185.

13 Moilanen JS, Finnilä S, Majamaa K: Lineage-specific selection in human mtDNA: lack of polymorphisms in a segment of MTND5 gene in haplogroup. J Mol Biol Evol 2003; 20: 2132-2142.

14 Ruiz-Pesini E, Mishmar D, Brandon M, Procaccio V, Wallace DC: Effects of purifying and adaptive selection on regional variation in human mtDNA. Science 2004; 303: 223-226.

15 Meinilä M, Finnilä S, Majamaa K: Evidence for mtDNA admixture between the Finns and the Saami. Hum Hered 2001; 52: $160-170$.

16 Niemi AK, Hervonen A, Hurme M, Jylhä M, Karhunen PJ, Majamaa K: Mitochondrial DNA polymorphisms associated with longevity in a Finnish population. Hum Genet 2003; 112: 29-33.

17 Torroni A, Bandelt HJ, Macaulay V et al: A signal, from human mtDNA, of postglacial recolonization in Europe. Am J Hum Genet 2001; 69: 844-852.

18 Finnilä S, Lehtonen MS, Majamaa K: Phylogenetic network for European mtDNA. Am J Hum Genet 2001; 68: 1475-1484.

19 Herrnstadt C, Elson JL, Fahy E et al: Reduced-median-network analysis of complete mitochondrial DNA coding-region sequences for the major African, Asian, and European haplogroups. Am J Hum Genet 2002; 70: 1152-1171.
20 Ruiz-Pesini E, Lapena AC, Diez-Sanchez C et al: Human mtDNA haplogroups associated with high or reduced spermatozoa motility. Am J Hum Genet 2000; 67: 682-696.

21 North KN, Yang N, Wattanasirichaigoon D, Mills M, Easteal S, Beggs AH: A common nonsense mutation results in alphaactinin-3 deficiency in the general population. Nat Genet 1999; 21: $353-354$.

22 Mills M, Yang N, Weinberger R et al: Differential expression of the actin-binding proteins, alpha-actinin-2 and -3 , in different species: implications for the evolution of functional redundancy. Hum Mol Genet 2001; 10: 1335-1346.

23 Finnilä S, Hassinen IE, Ala-Kokko L, Majamaa K: Phylogenetic network of the mtDNA haplogroup U in Northern Finland based on sequence analysis of the complete coding region by conformation-sensitive gel electrophoresis. Am J Hum Genet 2000; 66: $1017-1026$

24 De Benedictis G, Rose G, Carrieri G et al: Mitochondrial DNA inherited variants are associated with successful aging and longevity in humans. FASEB J 1999; 13: 1532-1536.

25 Ross OA, McCormack R, Curran MD et al: Mitochondrial DNA polymorphism: its role in longevity of the Irish population. Exp Gerontol 2001; 36: 1161-1178.

26 Ivanova R, Leapage V, Charron D, Schächter F: Mitochondrial genotype associated with French Caucasian centenarians. Gerontology 1998; 44: 349

27 Kadenbach B: Intrinsic and extrinsic uncoupling of oxidative phosphorylation. Biochim Biophys Acta 2003; 1604: 77-94.

28 Skulachev VP: Uncoupling: new approaches to an old problem of bioenergetics. Biochim Biophys Acta 1998; 1363: 100-124.

29 Huang H, Manton KG: The role of oxidative damage in mitochondria during aging: a review. Front Biosci 2004; 9: $1100-1117$

30 Zhang J, Dai J, Lu Y et al: In vivo visualization of aging-associated gene transcription: evidence for free radical theory of aging. Exp Gerontol 2004; 39: 239-247.

31 Speakman JR, Talbot DA, Selman C et al: Uncoupled and surviving: individual mice with high metabolism have greater mitochondrial uncoupling and live longer. Aging Cell 2004; 3: $87-95$.

32 Hagen T, Vidal-Puig A: Mitochondrial uncoupling proteins in human physiology and disease. Minerva Med 2002; 1: 41-57.

33 Coskun PE, Ruiz-Pesini E, Wallace DC: Control region mtDNA variants: longevity, climatic adaptation, and a forensic conundrum. Proc Natl Acad Sci USA 2003; 100: 2174-2176.

34 Mishmar D, Ruiz-Pesini E, Golik P et al: Natural selection shaped regional mtDNA variation in humans. Proc Natl Acad Sci USA 2003; 100: 171-176.

35 Torroni A, Huoponen K, Francalacci P et al: Classification of European mtDNAs from an analysis of three European populations. Genetics 1996; 144: $1835-1850$ 